\title{
Understanding How Research Experiences for Undergraduate Students May Foster Diversity in the Professorate
}

\author{
Burçin Tamer \\ Computing Research Association \\ 1828 L Street NW, Ste. 800 \\ Washington, DC 20036 \\ 202-266-2935, +1 \\ burcin@cra.org
}

\author{
Jane G. Stout \\ Computing Research Association \\ 1828 L Street NW, Ste. 800 \\ Washington, DC 20036 \\ 202-266-2937, +1 \\ jane@cra.org
}

\begin{abstract}
College and university professors serve as role models and leaders. Unfortunately, in computing fields, only a small fraction of the professorate is women and/or members of minority racial groups. To address this issue, the current research assessed the role of research experiences for undergraduate students (REUs) on underrepresented students' interest in pursuing a career as a computing professor. We found that REUs utilizing a set of specific practices are linked with underrepresented students' interest in becoming a computing professor. On the other hand, no specific REU practice was associated with majority students' (i.e., White and Asian men's) level of interest in becoming a professor. Thus, this research not only identifies aspects of REUs that may be especially important for increasing diversity in the professorate but also highlights that REUs may serve different purposes for underrepresented versus majority students.
\end{abstract}

\section{Categories and Subject Descriptors}

- Social and professional topics $\sim$ Computational science and engineering education - Social and professional topics $\sim$ Race and ethnicity - Social and professional topics $\sim$ Men $\bullet$ Social and professional topics $\sim$ Women

\section{Keywords}

undergraduate education; undergraduate research experiences; career; underrepresented students; professor

Permission to make digital or hard copies of all or part of this work for personal or classroom use is granted without fee provided that copies are not made or distributed for profit or commercial advantage and that copies bear this notice and the full citation on the first page. Copyrights for components of this work owned by others than ACM must be honored. Abstracting with credit is permitted. To copy otherwise, or republish, to post on servers or to redistribute to lists, requires prior specific permission and/or a fee. Request permissions from permissions@acm.org.

SIGCSE '16, March 02-05, 2016, Memphis, TN, USA

(C) 2016 ACM. ISBN 978-1-4503-3685-7/16/03 ..\$15.00

DOI: http://dx.doi.org/10.1145/2839509.2844573

\section{INTRODUCTION}

\subsection{Background}

The computer science academic pipeline lacks diversity among its undergraduate students, graduate students, and faculty [22] [24] [25] [33]. This is a problem for a number of reasons. First, a lack of diversity in computing innovation risks ignoring the needs of significant portions of the population [4] [21]. Furthermore, without contributions from a broad range of perspectives, the field cannot maximize productivity and creativity [16] [32]. In the current paper, we are interested specifically in the lack of diversity in the computing professorate. Research suggests that low diversity in the computing professorate may be inadvertently contributing to low diversity in the computing student body. Extant research indicates that when students experience a dearth of role models who "look like them" in the academy, their performance, motivation, and positive attitudes towards academics suffer (e.g., see [8] [17] [18] [31]). Thus, if the student body within computing is to become more diverse, it is important to showcase a diverse array of role models within the computing professorate.

One way to promote interest in pursuing a professorial job among underrepresented students may be through research experiences for undergraduate students (REUs). REU is an established tool for enhancing the undergraduate experience and increasing students' motivation to pursue graduate study, and academic research careers (e.g., [19] [20] [26] [27]). An ethnographic study of students' perceptions of their REU programs indicated that more than $90 \%$ of students' statements about their REU experiences were positive ([28]). Other research indicates that, participation in an REU increases students' persistence in their field ([22]), and undergraduate students to pursue graduate school ([27])

Importantly, existing research finds that students who are underrepresented men as well as women (URMW) tend to benefit more from REUs than White and Asian male students (i.e., "majority men"; MM). For instance, URMW students show a greater degree of improvement in academic skills, and postsecondary aspirations after participating in undergraduate research than MM students ([5] [6] [10] [27]). Thus a great deal of research suggests that REUs benefit URMW students to a greater degree than MM students, and may serve as a tool to increase the number of URMW individuals interested in pursuing professorial computing professions. 


\subsection{Understanding the nuances of the benefits of REUs on URMW students}

In the current research, we are interested in whether specific characteristics of REUs are particularly potent predictors of URMW students' aspirations for the professorate. Although REUs all share a common goal of exposing undergraduate students to scientific research methods, there is considerable variability in REU program components. For instance, while some REUs involve a great deal of collaboration and teamwork, others do not. REUs might also differ in social applicability of their research topic (e.g., Robotics research with medical versus industrial applications). These differences across programs can emerge based on a number of factors, such as the PI's area of expertise and resources available to the program.

Variability in the way REUs are orchestrated may, in turn, have differential impact on students' interest in wishing to pursue computing research in the future. Further, variability in REU infrastructure may have differential effects on different types of students (i.e., URMW versus MM students), such that only a subset of students may leave their REU particularly encouraged to pursue advanced studies in computing. Given that the field of computing research suffers from low diversity at all levels of the academic pipeline, our work sought to pinpoint REU characteristics that are particularly encouraging for URMW students' persistence in academic computing research.

In order to determine the types of REU characteristics that might be relevant for students' future career plans, we turn to the principles of Social Cognitive Career Theory (SCCT) [11] [13] and the extant literature on experiences of underrepresented students in computing.

SCCT indicates that key factors that guide individuals' career choices are outcome expectations (i.e., beliefs about the types of things one can achieve in their career), personal interest, and social support. Previously, scholars found that these factors indeed predicted students' persistence in computing disciplines [14] [15]. In the current study, we are interested in going a step further and teasing out conditions under which URMW students in particular may err towards a career in computing.

For instance, earlier studies have found that some outcome expectations for a career in computing carry more importance for URMW students compared to MM students. URMW students tend to be attracted to technical fields that are collaborative and have clear social applications ([9] [30]), suggesting that REUs fostering collaboration and socially relevant research may promote URMW students' interest in pursuing research in the future.

Moreover, underrepresented REU students are less likely than their MM peers to have had prior exposure to mentorship (i.e., social support from role models and experts; [1] [7] [28]). As such, URMW students may be especially sensitive to the benefits of being mentored during an REU, which involves learning about career options, and gaining exposure to all facets of the research and dissemination process. In this sense, exposure to the research process as well as graduate school preparation during REUs may be more strongly linked with URMW students' intentions to pursue a professorial career compared to the intentions of MM students.

In sum, we have reason to believe that particular REU characteristics might be effective in promoting URMW students' interest in pursuing scholarly computing research as a career path. The current research aims to make a contribution to existing research on the benefits of REUs on URMW students' persistence in computing research by assessing the effect of common REU practices on students' career aspirations.

\section{DATA and METHODS}

\subsection{Participants and procedure}

During the fall of 2014, 101 undergraduate students who had completed an REU during the summer of 2014 participated in this study. Students were recruited from computing departments across the United States to complete the Computing Research Association's Center for Evaluating the Research Pipeline (CERP) annual student survey. ${ }^{1}$ Students who indicated that they had participated in any of the following during the summer of 2014 were included in our sample: (a) an undergraduate research experience at their home institution, (b) an undergraduate research experience at another institution or (c) a research internship in an industry or government lab.

Within our dataset were two demographic subgroups of interest. The first was underrepresented minority men, including those of Black/African American or Hispanic/Latino descent, and women of all racial and ethnic backgrounds (URMW students, $n=52$ ). The second group was White and Asian men. We refer to this group as "majority men" (MM, $n=49)$.

\subsection{Measures}

The current report focuses on the following subset of measures from CERP's fall 2014 survey that assessed students' career intentions, and experiences during their summer REU:

\subsubsection{Outcome variable: Interest in becoming a computing professor.}

Students responded to a single item asking "How interested are you in having a computing job like the one below after you finish your highest degree? College/University professor in computing field", using a scale ranging from (1) very disinterested to (5) very interested.

\subsubsection{Predictors: REU characteristics.}

Students completed a series of survey questions pertaining to their level of exposure to a set of REU characteristics during their REU. While some of the characteristics were measured using a single survey item, other characteristics were aggregate measures that were constructed by averaging across multiple items. Survey items for each REU characteristic variable, and reliability statistics, when appropriate, are listed below.

Collaboration: Collaboration with others was measured via two items (Cronbach's $\alpha=0.86$ ): "How much experience did you gain collaborating with colleagues?", (1) none - (5) a lot; and "How much knowledge have you gained in the following areas as a result of your research experience? How to work collaboratively with others", (1) none - (5) a lot.

Social Impact: Information on how computing can have social impact was measured via a single item: "How much knowledge have you gained in the following areas as a result of your research

\footnotetext{
1 CERP administers an annual survey each fall semester to undergraduate student computing majors from a sample of universities and colleges across the county. Survey questions pertain to past research and professional experiences, with a particular focus on factors relevant to career preparation. For more information about CERP's survey research, visit http://www.cra.org/cerp/data-buddies.
} 
Figure 1. Analytical Model

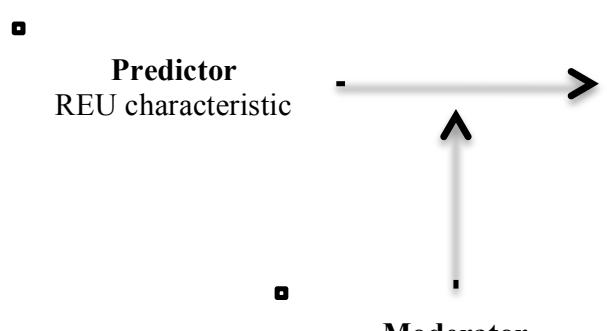

Moderator

Demographic group
口

\section{Covariates -}

experience? How computing can make a positive contribution to society", (1) none - (5) a lot.

Career Options: Exposure to computing career options was measured via a single item: "How much knowledge have you gained in the following areas as a result of your research experience? What career options are available within computing", (1) none - (5) a lot.

Research Skills: Exposure to research skills was measured via five items (Cronbach's $\alpha=0.87$ ): "How much experience did you gain in the following activities? Using scientific methods to test a hypothesis; Generating hypotheses; Collecting data or conducting experiments; Analyzing data with statistics or other tools; Explaining results", (1) none - (5) a lot.

Research Dissemination: Exposure to the research dissemination process was measured via four items (Cronbach's $\alpha=0.86$ ): "How much experience did you gain in the following activities? Summarizing published research results; Writing or co-authoring a research paper or report; Presenting a research paper or report; Publishing a research paper or report", (1) none - (5) a lot.

Research Involvement: Involvement in the design of a research project was measured via three items (Cronbach's $\alpha=0.83$ ): How much experience did you gain in the following activities? The design of the research project(s); What research techniques/materials were used; Deciding what to do next (e.g. follow-up studies)", (1) none - (5) a lot.

Admissions: Learning about the graduate admission process was assessed via two items (Cronbach's $\alpha=0.94$ ): How much knowledge have you gained in the following areas as a result of your research experience? Criteria for admission to graduate programs, How to select the right graduate program for you", (1) none - (5) a lot.

Graduate Student Life: Learning about graduate student life was measured via a single item: "How much knowledge have you gained in the following areas as a result of your research experience? What it is like to be a graduate student in computer science or computer engineering", (1) none - (5) a lot.

\subsubsection{Covariates ${ }^{2}$}

We measured the following demographic characteristics, which served as covariates during data analyses.

Parental education level: Students indicated parental education level for up to two parents using the following options: Less than high school; High school graduate or GED; Some college or Associate's degree; Bachelor's degree; Master's degree; $\mathrm{PhD}$ or Professional degree (MD, JD, Ed.D, etc...). Among students who reported parental education level for two parents, we used the highest parents' education level as our measure of parental education level.

Class standing: Students indicated their class standing using the following categories: first year, second year, third year, fourth year, and fifth year or greater.

Department type: We conducted a content analysis of students' home institutions' computing degree program websites in order to group students' department type by the highest degree granted in their department. Department type was coded into three categories, based on the highest degree awarded in student's home computing department: B.S., M.S., or Ph.D.

Major grade point average: Students reported their grade point average (GPA) in their majors, using a range from 0-4.

\section{RESULTS}

We ran multiple linear regression analyses to assess whether the relationship between characteristics of an REU program and students' professorial intentions was moderated by (depended on) students' demographic group (URMW vs. MM). Figure 1 illustrates our analytical model showing the moderating role of demographic group in determining the impact of REU

\footnotetext{
${ }^{2}$ Covariates are known correlates of outcome variables, and are included in statistical models so that any observed effects of predictors and moderators on outcome variables are true over and above the effects of our covariates on outcome measures.
} 
Table 1. Simple Effects of Eight REU characteristics for URMW and MM students

\begin{tabular}{|c|c|c|c|c|c|c|}
\hline \multirow[b]{2}{*}{ REU characteristic } & \multicolumn{3}{|c|}{ URMW Students } & \multicolumn{3}{|c|}{ MM Students } \\
\hline & $\begin{array}{c}\text { Average } \\
\text { simple effect }\end{array}$ & $\begin{array}{c}95 \% \text { CI lower } \\
\text { bound }\end{array}$ & $\begin{array}{l}95 \% \text { CI upper } \\
\text { bound }\end{array}$ & $\begin{array}{c}\text { Average } \\
\text { simple effect }\end{array}$ & $\begin{array}{l}95 \% \text { CI lower } \\
\text { bound }\end{array}$ & $\begin{array}{l}95 \% \text { CI upper } \\
\text { bound }\end{array}$ \\
\hline Collaboration & $1.61 *$ & 0.28 & 2.84 & -0.11 & -1.56 & 1.31 \\
\hline Social Impact & $1.46^{*}$ & 0.23 & 2.68 & -0.30 & -1.52 & 0.91 \\
\hline Career Options & 0.71 & -0.43 & 1.77 & -0.82 & -2.02 & 0.44 \\
\hline Research Skills & 0.74 & -0.62 & 2.04 & 0.80 & -0.72 & 2.42 \\
\hline Research Dissemination & 1.08 & -0.09 & 2.27 & 1.12 & -0.23 & 2.51 \\
\hline Research Involvement & 0.80 & -0.44 & 2.10 & 0.71 & -0.93 & 2.18 \\
\hline Admissions & $1.18^{*}$ & 0.21 & 2.23 & 0.26 & -0.95 & 1.50 \\
\hline Graduate Student Life & $2.01 *$ & 0.99 & 3.01 & -0.10 & -1.44 & 1.23 \\
\hline
\end{tabular}

Note. Simple effects calculated based on an OLS regression model. ${ }^{*} p<.05$.

characteristics (predictor variable) on undergraduate students' interest in becoming a professor in a computing field (outcome variable). We included a moderating variable in our model to test for the interaction between students' demographic group and REU characteristics. A "moderation" (or interaction) effect occurs when the relationship between a predictor variable (e.g., an REU characteristic) and an outcome variable (e.g., students' level of interest in becoming a college/university professor in a computing field) depends on a moderator variable (e.g., demographic group: MM vs. URMW).

As an example of a moderated relationship, suppose that students who are exposed to a higher degree of collaboration in their REU (predictor variable) are subsequently more interested in becoming a professor of computing (outcome variable). However, the relationship between exposure to collaboration and professorial intentions is stronger for one demographic group of students than another (moderator variable). Specifically, it could be that REUs fostering collaboration are particularly likely to promote interest in becoming a professor among URMW students, relative to MM students. Thus, moderation analyses can explain "when" or "for whom" the effects of a predictor variable are related to a particular outcome. In total, we ran eight separate multiple regression models (one for each REU characteristic) using the regression equation seen in Equation 1. We do not present regression output for our full models, given the conditional nature of our analyses (i.e., interpretation of the interaction term in our models is contingent on our dummy coding scheme for Demographic Group, such that output for the Predictor variable is only relevant to students who were coded as 0$).^{3,4}$ Instead, we only present output for simple effects of our main predictor and moderator variables in Table 1.

\section{Equation 1. Linear Regression Model}

Interest in Being a Professor

$$
\begin{aligned}
& =\beta_{o}+\beta_{1} \times \text { Parental Education Level } \\
& +\beta_{2} \times \text { Class Standing } \\
& +\beta_{3} \times \text { Department Type }+\beta_{4} \times \text { Major GPA } \\
& +\beta_{5} \times \text { REU Characteristic } \\
& +\beta_{6} \times \text { Demographic Group } \\
& +\beta_{7} \times \text { REU Char. } \times \text { Dem. Group }
\end{aligned}
$$

Simple effects in Table 1 show the effect of a change in the predictor (REU Characteristic) on the outcome for given values of

\footnotetext{
${ }^{3}$ For further discussion of conditional interpretation for interaction terms, see [1] [2] [11].

${ }^{4}$ Full regression output is available from the first author.
}

the moderator variable (Demographic Group). Average simple effects shown in Table 1 illustrate the effect of moving from the minimum value of the Likert-type scale (i.e. exposure to REU characteristic $=1$ ) to the maximum value of the scale (i.e. exposure to REU characteristic = 5) for URMW and MM students, respectively. As an example, URMW students who rate their experience of collaboration as "a lot" as opposed to "none" are expected to rate their interest in becoming a college/university professor 1.61 points higher on average.

Our results show that URMW students that experienced greater collaboration (avg. effect $=1.61,95 \% \mathrm{CI}=[0.28,2.84])$, learned more about the social impacts of a career in computing (avg. effect $=1.46,95 \% \mathrm{CI}=[0.23,2.68])$, learned more about the graduate school admissions process (avg. effect $=1.18,95 \% \mathrm{CI}=$ $[0.21,2.23])$, and became more familiar with graduate student life (avg. effect $=2.01,95 \% \mathrm{CI}=[0.99,3.01]$ ) during their REU showed greater interest in becoming a computing professor when surveyed the fall after their summer REU. However, MM students' interest in pursuing a career as a computing professor was not influenced by their REU experience.

\section{DISCUSSION}

The current research was designed to better understand how REUs might be an effective means for promoting diversity in the computing professorate. We found that URMW students who participated in REUs reported greater intentions to pursue a career as a college or university professor when they gained experience collaborating, learned about social impacts of a career in computing research, gained knowledge of the graduate admissions process, and were familiarized with graduate student life. These REU characteristics likely bring URMW students a combination of knowledge and interest necessary to pursue a career as a computing professor. Collaborating within an academic setting on research projects may illustrate to the students that they are capable of taking on tasks that a professor would be performing. In addition to highlighting their capabilities, the experience of collaboration also shows that working in computing research need not be a solitary experience. Furthermore, understanding the social applications of scholarly computing research may reveal to students the potential impact of computing research on their communities. Finally, information on how to get into graduate school as well as exposure to graduate student life may increase students' interest in the professorate by equipping them with the information they need to get started on a professorial career path. These explanations are in line with the theoretical and empirical literature on the experiences of underrepresented students in computing fields as discussed in our introduction section. 
Interestingly, MM students' level of interest in becoming a professor was not associated with any of the eight REU practices we examined. This suggests that REUs may have a different meaning and purpose for MM students than URMW students. For instance, it could be the case that participating in an REU benefits MM students' resumes, and yields new professional contacts, but does not necessarily influence their personal goals and plans.

An alternative explanation for our observed lack of any association between REU characteristics and intentions to pursue a career as a professor for MM students may be that MM students have systematically higher or lower levels of interest in a professorship than URMW students regardless of how their REU was organized. That is, there may have been less variability in MM students' professorial intentions the URMW students, affording our analytic models less opportunity to predict MM students' intentions. We tested this possibility using a difference of means test URMW students' versus MM students' interest levels in becoming a professor; we found no group difference $(t(98)=0.72, p=0.47)$.

We acknowledge that the current work cannot make a causal claim about REU dynamics on URMW students' aspirations for the future, because our data were obtained at a single point in time and are therefore correlational. With this caveat in mind, this research suggests that REUs with a certain set of characteristics may be an effective means for diversifying the computing research pipeline in the long term. By promoting interest in the professorate among URMW undergraduate students, REUs have the capacity to diversify the types of role models that future generations of women, and men from racial minority groups interact with and aspire to become.

\section{ACKNOWLEDGMENTS}

This research is sponsored by two grants from the National Science Foundation awarded to the Computing Research Association: CNS-1246649 and DUE-1431112. We wish to thank Heather Wright for assistance with data collection, and Betsy Bizot, Tracy Camp, and Ama Nyame-Mensah for feedback on an earlier draft of this paper. We also wish to thank participating departments of The Data Buddies Project for contributing to the data source for this paper (participating departments can be found here: http://cra.org/cerp/our-buddies/list-of-data-buddies).

\section{REFERENCES}

[1] Aiken, L. S., \& West, S. G. 1991. Multiple regression: Testing and interpreting interactions. Thousand Oaks, CA: Sage.

[2] Bauer, D. J., \& Curran, P. J. 2005. Probing interactions in fixed and multilevel regression: Inferential and graphical techniques. Multivariate Behavioral Research. 405(3), 373400.

[3] Bova, B. 2000. Mentoring revisited: The black woman's experience. Mentoring and Tutoring. 8, 5-16.

[4] Camp, T. 2012. Computing, we have a problem. $A C M$ Inroads. 3, 34 - 40.

[5] Campbell, A., \& Skoog, G. 2004. Preparing Undergraduate Women for Science Careers. Journal of College Science Teaching. 33, 24-26.

[6] Chang, M., Sharkness, J., Hurtado, S., \& Newman, C. 2014. What matters in college for retaining aspiring scientists and engineers from underrepresented racial groups. Journal of Research in Science Teaching. 51, 555-580
[7] Committee on Science, Engineering \& Public Policy. 2011. Expanding Underrepresented Minority Participation: America's Science and Technology Talent at the Crossroads. National Academies Press.

[8] Dasgupta, N. 2011. Ingroup experts and peers as social vaccines who inoculate the self-concept: The stereotype inoculation model. Psychological Inquiry. 22, 231-246.

[9] Diekman, A. B., Brown, E. R., Johnston, A. M., \& Clark, E. K. 2010. Seeking congruity between goals and roles: A new look at why women opt out of science, technology, engineering, and mathematics careers. Psychological Science. 21, 1051-1057.

[10] Jones, M. T., Barlow, A. E. L., \& Villarejo, M. 2010. Importance of Undergraduate Research for Minority Persistence and Achievement in Biology. Journal of Higher Education. 81, 82-115.

[11] Kam, C. D. \& Franzese Jr., R. J. 2007. Modeling and Interpreting Interactive Hypotheses in Regression Analysis. Ann Arbor: University of Michigan Press.

[12] Lent, R. W., Brown, S. D., and Hackett G. 1994. Toward a Unifying Social Cognitive Theory of Career and Academic Interst, Choice, and Performance. Journal of Vocational Behavior. 45, 79-122.

[13] Lent, R. W., Brown, S. D., and Hackett G. 2002. Social Cognitive Career Theory. In Duane Brown, editor, Career Choice and Development, 255-311. John Wiley and Sons, San-Francisco, 4th. Edition.

[14] Lent, R. W., Lopez Jr., A. M., Lopez, F. G., and Sheu, H-B. 2008. Social cognitive career theory and the prediction of interests and choice goals in the computing disciplines. Journal of Vocational Behavior, 73, 52-62.

[15] Lent, R. W., Lopez, F. G., and Sheu, H-B., Lopez Jr., A. M. 2011. Social cognitive predictors of the interests and choices of computing majors: Applicability to underrepresented students. Journal of Vocational Behavior, 78, 184-192.

[16] Leung, K., Maddux, W., Galinsky, A. D. \& Chiu, C-Y. 2008. Multicultural experience enhances creativity: The when and how. American Psychologist. 63,169-181.

[17] Lockwood, P., and Kunda, Z. 1997. Superstars and me: Predicting the impact of role models on the self. Journal of Personality and Social Psychology. 73, 91-103.

[18] Lockwood, P. 2006. Someone like me is successful: Do college students need same-gender role models? Psychology of Women Quarterly. 30,36-46

[19] Lopatto, D. 2004. Survey of undergraduate research experiences (SURE): First findings. Cell Biology Education. 3, 270-277.

[20] Lopatto, D. 2007. Undergraduate research experiences support science career decisions and active learning. Cell Biology Education. 6, 297-306.

[21] Margolis, J., and Fisher, A. 2001. Unlocking the clubhouse: Women in computing. The MIT Press.

[22] Nagda, B. A., Gregerman, S. R., Jonides, J., von Hippel, W., \& Lerner, J. S. 1998. Undergraduate student-faculty research partnerships affect student retention. The Review of Higher Education, 22(1), 55-72.

[23] National Science Foundation. 2014a. National Center for Science and Engineering Statistics, special tabulations of 
U.S. Department of Education, National Center for Education Statistics, Integrated Postsecondary Education Data System, Completions Survey, 2002-12. TABLE 7-2. Doctoral degrees awarded to women, by field: 2002-12. Retrieved from:

http://www.nsf.gov/statistics/wmpd/2013/tables.cfm

[24] National Science Foundation. 2014b. National Center for Science and Engineering Statistics, special tabulations of U.S. Department of Education, National Center for Education Statistics, Integrated Postsecondary Education Data System, Completions Survey, 2002-12. TABLE 6-4. Master's degrees awarded to women, by field, citizenship, and race or ethnicity: 2002-12. Retrieved from:

http://www.nsf.gov/statistics/wmpd/2013/tables.cfm

[25] National Science Foundation. 2014c. National Center for Science and Engineering Statistics (NCSES). Bachelor's degrees awarded, by race or ethnicity, citizenship, sex, and field: 2012. Table 9-7. Retrieved from http://www.nsf.gov/statistics/wmpd/2013/tables.cfm.

[26] Nyame-Mensah, A. Tamer, N. B. and Stout, J. G. 2015. Understanding How Summer Research Experiences Can Foster Diversity In Computing Research. Computing Research Association: Washington, DC. Available from: $\mathrm{http} / / / \mathrm{cra}$.org/cerp/research-findings.

[27] Russell, S. H., Hancock, M. P., \& McCullough, J. 2007. The pipeline: benefits of undergraduate research experiences. Science. 316, 548-549.
[28] Seymour, E., Hunter, A.B., Laursen, S. L. and DeAntoni, T. (2004) 'Establishing the benefits of research experiences for undergraduates in the sciences: First findings from a threeyear study', Science Education, 88(4), 493-534. doi: 10.1002/sce.10131.

[29] Stanley, C. A., \& Lincoln, Y. S. 2005. Cross-race faculty mentoring. Change: The Magazine of Higher Learning. 37, 44-50.

[30] Stephens, N. M., Fryberg, S. A., Markus, H. R., Johnson, C. S., \& Covarrubias, R. 2012. Unseen disadvantage: How American universities' focus on independence undermines the academic performance of first-generation college students. Journal of Personality and Social Psychology. 102, 1178-1197.

[31] Stout, J. G., Dasgupta, N., Hunsinger, M., \& McManus, M. 2011. STEMing the tide: Using in-group experts to inoculate women's self-concept in science, technology, engineering, and mathematics (STEM). Journal of Personality and Social Psychology. 100, 255-270.

[32] Thomas, D. A. 2004. Diversity as strategy. Harvard Business Review. 82 (9), 98-108.

[33] Zweben, S., \& Bizot, B. 2015. 2014 Taulbee survey: Relentless growth in undergraduate CS enrollment; Doctoral degree production remains strong, but no new record. Computing Research News. 27, 5. Available from $\mathrm{http}: / /$ cra.org/resources/crn-online 